\title{
Possibilities of fungal biodegradation of antimalarial and anticancer primaquine in the environment
}

\author{
Igor A. Parshikov ${ }^{1}$ and Evgeny I. Zaraisky ${ }^{1}$ \\ 'Institute of Applied Mechanics, RAS, Moscow, Russia 125040
}

(Received 29 May, 2019; accepted 11 July, 2019)

\begin{abstract}
After human and veterinary therapy primaquine is not completely removed at municipal wastewater treatment plants and therefore are discharged into the environment. We studied changes of the structure of primaquine by fungus Beauveria bassiana widely present in nature. Two peaks of metabolites were observed by HPLC in extract of incubation mixture. Proton nuclear magnetic resonance spectra and electrospray ionization mass spectra analysis of the products confirmed the formation of $N$-acetylprimaquine, $24.5 \%$ of total extract peak area at $265 \mathrm{~nm}$ and $N$-formylprimaquine, $2.8 \%$ of total extract peak area at $265 \mathrm{~nm}$.
\end{abstract}

Key words : Biodegradation, Acetylation, Formylation, Beauveria bassiana

\section{Introduction}

Primaquine is 8-aminoquinoline drug has been used against malarial disease (Graves et al., 2018; Parshikov et al., 2018a) for over 50 years. Recently, primaquine has also been used for the treatment of cancer (Choi et al., 2016).

Primaquine, obtained after the therapy of humans and animals, is not completely removed at the treatment plant and, therefore, is discharged into the wastewater (Heberer, 2002). Wastewater treatment processes were often not designed for removing compounds from wastewater (Kolpin et al., 2002). Organic waste can turn into new and more resistant compounds that can be released in addition to the original.

Many researches were dedicated to bioconversions of primaquine for studies of pathways of transformations this drug in living organisms and by microorganisms.

Different metabolites of primaquine are produced during metabolism in animals and humans. The widespread metabolite in living organisms and in microorganisms cells is carboxyprimaquine (Hufford et al., 1983). Another isolated major microbial metabolite of primaquine is $\mathrm{N}$-acetyl derivative (Hufford et al., 1983). This metabolite is produced by almost all species of Streptomyces. Other ways of primaquine transformation in living organisms are desalkylation, formation of $N$-hydroxyderivatives, 5- and 6-hydroxyderivatives and 6-metoxy-8hydroxyaminoquinoline etc (Vale et al., 2009).

We have investigated the transformation of primaquine by the fungus Beauveria bassiana. This fungus widely present in nature and was capable for transforming many organic compounds (Parshikov et al., 2002). So that fungus may be used as model for biodegradation of primaquine in wastewaters.

\section{Materials and Methods}

Strain Beauveria bassiana ATCC 7159 was obtained from American Typical Cultures Collection.

Stock cultures were maintained on agar slants. The spores were washed from the surface of the agar with $5 \mathrm{~mL}$ of sterilized water and transported

*Corresponding author's email : akadmah@gmail.com 
to $500 \mathrm{~mL}$ flasks, each with $100 \mathrm{~mL}$ of a medium containing (per liter): sucrose, $30.0 \mathrm{~g}$; peptone, $5.0 \mathrm{~g}$; $\mathrm{NaCl}, 3.0$ g; $\mathrm{NaNO}_{3}, 3.0$ g; $\mathrm{KH}_{2} \mathrm{PO}_{4}, 5.0$ g; $\mathrm{MgSO}_{4} 7 \mathrm{H}_{2} \mathrm{O}, 0.5 \mathrm{~g} ; \mathrm{KCl}, 0.5 \mathrm{~g} ; \mathrm{FeSO}_{4}, 0.1 \mathrm{~g}$; and $\mathrm{MnSO}_{4^{\prime}} 1 \mathrm{mg}$ in deionized water. The $\mathrm{pH}$ was adjusted to 5.0. Cultures were grown for 48 hours on a rotary shaker at $28{ }^{\circ} \mathrm{C}$ with shaking at $180 \mathrm{rpm}$ (Parshikov and Khasaeva, 2018b).

Primaquine diphosphate was dissolved in deionized water and filter-sterilized; $1 \mathrm{~mL}$ was added to each flask to make a final concentration of $100 \mathrm{mg}$ / $\mathrm{mL}$. After dosing, the cultures were incubated for an additional 10 days at $28^{\circ} \mathrm{C}$ with shaking at $180 \mathrm{rpm}$. Cultures without primaquine and dosed, noninoculated controls were also incubated.

Mycelia were separated from the medium with filter paper on a Büchner funnel. Metabolites were extracted from the culture fluid with three equal volumes of methylene chloride (under $\mathrm{pH} 10$ - 11) in a separatory funnel; the solvent was evaporated in vacuo on a rotary evaporator.

Extracts were analyzed by reversed-phase highperformance liquid chromatography (HPLC). A Waters 2690 separation module chromatograph equipped with the Waters 996 photodiode array detector, monitored at $265 \mathrm{~nm}$, was fitted with a 4.6 $\times 10 \mathrm{~mm}$ Phenomenex Prodigy $5 \mathrm{~mm}$ ODS-3 column. The mobile phase components were solvent $\mathrm{A}$ $(0.7 \%$ triethylamine in water, $\mathrm{pH} 7.5)$ and solvent $\mathrm{B}$ (methanol). The mobile phase (flow rate $=0.2 \mathrm{ml} /$ min) was a linear 50-min gradient fron $45 \%$ to $80 \%$ solvent $\mathrm{B}$. The resulting biotransformation products were isolated using preparative reversed phase HPLC with using Waters Delta Prep 4000 chromatograph fitted with a semipreparative $10 \times 250 \mathrm{~mm}$ Phenomenex Prodigy $5 \mathrm{~mm}$ ODS-3 column (flow rate $=2.5 \mathrm{ml} / \mathrm{min}$ ).

Liquid chromatography/electrospray ionization mass spectrometry (LC/ESI MS) was performed using a Hewlett-Packard 1090L/M HPLC system with a $2.0 \times 250 \mathrm{~mm}$ Prodigy 5-mm ODS-3 column and a Hewlett-Packard 5989B quadrupole mass spectrometer operated in the positive-ion electrospray mode. The mobile phase was a linear 40-min gradient from $95 \%$ water $/ 5 \%$ acetonitrile to $5 \%$ water $/ 95 \%$ acetonitrile, with constant $0.1 \%$ formic acid, at a flow rate of $0.2 \mathrm{mlmin}^{-1}$.

${ }^{1} \mathrm{H}$ nuclear magnetic resonance (NMR) spectral analyses were performed at $500 \mathrm{MHz}$ on a Bruker AM 500 NMR spectrometer (Bruker Instruments, Billerica, Mass.) at $28{ }^{\circ} \mathrm{C}$. Compounds were dis- solved in deuterated dimethyl sulfoxide; chemical shifts are reported on the ppm scale.

\section{Results}

High-performance liquid chromatography (HPLC) analysis of the methylene chloride extracts showed that only Beauveria bassiana transformed primaquine<smiles>COc1cc(NC(C)CCCN)c2ncccc2c1</smiles>

\section{Primaquine}<smiles>COc1cc(N(C=O)C(C)CCCN)c2ncccc2c1</smiles>

\section{$N$-Formyl primaquine (P-1)}

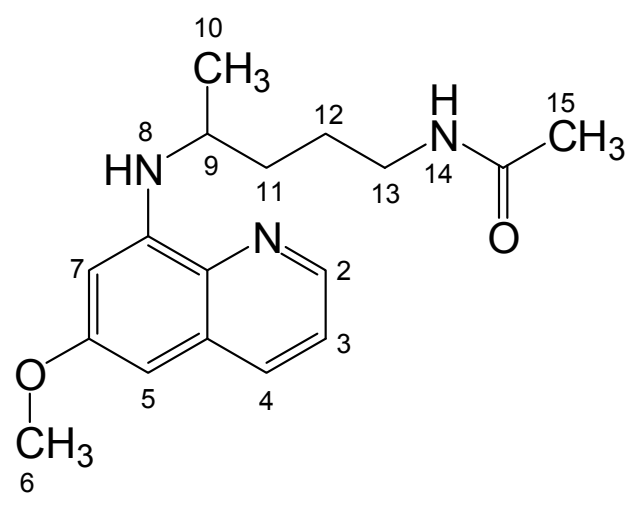

\section{N-Acetyl primaquine (P-2)}

Fig. 1. Structures of primaquine and its metabolites. 
to two different metabolites (Fig. 1) showed residual primaquine eluting at $28.4 \mathrm{~min}$ and two metabolites (P-1 and P-2) that were not found in controls eluted at at 22.6 and $44.3 \mathrm{~min}$, respectively. Other peaks were found but were also detected in the controls. After 10 days, as shown by the peak areas at 265 $\mathrm{nm}, 72.7 \%$ of the added primaquine remained.

Metabolite P-1, 2.8\% of total extract peak area at $265 \mathrm{~nm}$, had a UV absorption spectrum with $\lambda_{\max }=$ 267, 301 and $384 \mathrm{~nm}$. The positive-ion ESI mass spectrum obtained at $+200 \mathrm{~V}$ included ions at $\mathrm{m} / \mathrm{z}$ $288(5)[\mathrm{M}+\mathrm{H}]^{+}, 271(12)\left[\mathrm{M}+\mathrm{H}-\mathrm{NH}_{3}\right]^{+}$and $203(100)$ $\left[\mathrm{M}+\mathrm{H}-\mathrm{C}_{5} \mathrm{H}_{10} \mathrm{NH}_{2}\right]^{+}$. The most likely metabolite is $\mathrm{N}$ formyl primaquine formylated on the secondary amine (Fig. 1). The ${ }^{1} \mathrm{H}$ NMR spectrum of $\mathrm{P}-1$ showed at Table 1 . The basics peaks obtained from $\mathrm{N}$-formylprimaquine $(\mathrm{m} / \mathrm{z} 203)$ and from $\mathrm{N}$ acetylprimaquine $(\mathrm{m} / \mathrm{z} 175)$ were showed by the positive ESI mass spectrometry. Loss of the sidechain from the protonated molecule of $\mathrm{N}$ formylprimaquine is reason of formation the ion at $m / z 203$.

Metabolite P-2, 24.5\% of total extract peak area at $265 \mathrm{~nm}$, had a UV absorption spectrum with $\lambda_{\max }=$ 265 and $362 \mathrm{~nm}$. The positive-ion ESI mass spectrum obtained at $+200 \mathrm{~V}$ included ions at $\mathrm{m} / \mathrm{z} 302$ (5) $[\mathrm{M}+\mathrm{H}]^{+}, 175(100)\left[\mathrm{M}+\mathrm{HC}_{5} \mathrm{H}_{10} \mathrm{NH}_{2} \mathrm{C}_{2} \mathrm{H}_{3} \mathrm{O}\right]^{+}$and 132 (9) $\left[\mathrm{M}+\mathrm{H}-\mathrm{C}_{2} \mathrm{H}_{3} \mathrm{OC}_{5} \mathrm{H}_{10} \mathrm{NH}_{2} \mathrm{C}_{2} \mathrm{H}_{3} \mathrm{O}\right]^{+}$. Loss of the sidechain from the protonated molecule results in a base peak at $m / z 175$ which identical with the base peak for starting material. The fragments are nearly identical with those seen for the starting material, so modifying parts that are lost makes sense. The ${ }^{1} \mathrm{H}$ NMR spectrum of P-2 showed at Table 1. The metabolite was identified as $\mathrm{N}$-acetyl primaquine (Fig. $1)$.

\section{Discussion}

Primaquine is an important antimalarial and anticancer (Choi et al., 2016) agent and it is used in medicine for a long time. Unlike other 8aminoquinolines, primaquine therapy successfully eliminates the sporozoites, merozoites, and gametes residing outside of the infected erythrocytes. The most widespread pathways for the conversions of primaquine by different organisms were studied in different laboratories.

Unfortunately, 8-hydroxylaminoquinolines formed in humans from parent compounds have the hemolytic activity (Bolchoz et al., 2001). Many investigations concerning modification of structure of primaquine by microorganisms were realized (Hufford et al., 1983). However, many studied types of biotransformation reactions on primaquine such as alkylation and acetylation of the primary amine's group, the formation of carboxyprimaquine, hydroxylation of aromatic ring can not help to avoid the problem of 8-hydroxylaminoquinolines formation in human organisms from primaquine and his

Table 1. ${ }^{1} \mathrm{H}$ NMR parameters for primaquine and its metabolites produced by B. bassiana

\begin{tabular}{|c|c|c|c|c|c|c|}
\hline \multirow[b]{2}{*}{ Proton } & \multicolumn{3}{|c|}{ Chemical shift, $\mathrm{ppm}^{\mathrm{a}}$} & \multicolumn{3}{|c|}{ Coupling constants, J, in $\mathrm{Hz}$} \\
\hline & Primaquine & P-1 & $\mathrm{P}-2$ & Primaquine & $\mathrm{P}-1$ & $\mathrm{P}-2$ \\
\hline $\mathrm{H} 2$ & 8.53 & 8.54 & 8.52 & $\begin{aligned} J_{2,3} & =4.3 \\
J_{24} & =1.7\end{aligned}$ & $\begin{array}{l}J_{2,3}=4.3 \\
J_{24}=1.7\end{array}$ & $\begin{aligned} J_{2,3} & =4.1 \\
J_{24} & =1.7\end{aligned}$ \\
\hline H3 & 7.42 & 7.43 & 7.41 & $J_{3,4}^{2,4}=8.4$ & $J_{3,4}^{2,4}=8.4$ & $J_{3,4}^{2,4}=8.4$ \\
\hline $\mathrm{H} 4$ & 8.07 & 8.08 & 8.06 & & & \\
\hline H5 & 6.47 & 6.47 & 6.46 & $J_{5,7}=2.6$ & $J_{5,7}=2.6$ & $J_{5,7}=2.6$ \\
\hline H6 & 3.81 & 3.81 & 3.81 & & & \\
\hline H7 & 6.28 & 6.30 & 6.24 & & & \\
\hline $\mathrm{H} 8$ & 6.14 & & 6.10 & $J_{89}=8.6$ & & $J_{89}=8.8$ \\
\hline H9 & 3.65 & 3.71 & 3.61 & & & \\
\hline H10 & 1.21 & 1.23 & 1.19 & $J_{9,10}=6.5$ & $J_{9,10}=6.5$ & $J_{9,10}=6.4$ \\
\hline H11 & $1.58-1.70$ & $1.58-1.70$ & $1.43-1.53,1.64$ & & & \\
\hline H12 & $1.58-1.70$ & $1.58-1.70$ & $1.43-1.53,1.64$ & & & \\
\hline $\mathrm{H} 13$ & 2.76 & 2.75 & 3.03 & $J_{12,13}=7.3$ & $J_{12,13}=7.3$ & $J_{12,13}=7.3$ \\
\hline H14 & & & 7.78 & & & \\
\hline H15 & & & 1.76 & & & \\
\hline H16 & & 8.10 & & & & \\
\hline
\end{tabular}

${ }^{\text {a }}$ Dissolved in deuterated dimethyl sulfoxide. 
derivatives (Hufford et al., 1983; Bolchoz et al., 2001).

Formation of $N$-formylated or $N$-acetylated derivatives in position 8 - of primaquine molecule (Fig. 1) might be able to help to avoid formation 8hydroxylaminoquinolines in environment and human organisms.

We observed that B. bassiana was capable for the formation of the $\mathrm{N}$-formylated derivative at secondary amine's group and of the $N$-acetylated derivative at the primary amine's group of the side chaine of primaquine. Of the many organisms present in the environment $\mathrm{B}$. bassiana models only one possibility of changing the structure of primaquine from the variety of other possible ways of its biodegradation.

\section{Acknowledgement}

We thank the Institute of Applied Mechanics, Russian Academy of Sciences, for financial support of this work.

\section{References}

Bolchoz, L.J., Budinsky, R.A., McMillan, D.C., Jollow, D.J. 2001. Primaquine-induced hemolytic anemia: formation and hemotoxicity of the arylhydroxylamine metabolite 6-methoxy-8-hydroxylaminoquinoline. J. Pharmacol. Exp. Ther. 297 (2) : 509-515.

Choi, A.R., Kim, J.H., Woo, Y.H., Kim, H.S. and Yoon, S. 2016. Drugs primaquine and chloroquine have different sensitization effects with anti-mitotic drugs in resistant cancer cells. Anticancer Res. 36 (4) : 1641-
1648.

Graves, P.M., Choi, L., Gelband, H. and Garner, P. 2018. Primaquine or other 8-aminoquinolines for reducing Plasmodium falciparum transmission. Cochrane Database Syst. Rev. 2 : CD008152.

Heberer, T. 2002. Occurrence, fate, and removal of pharmaceutical residues in the aquatic environment: a review of recent research data. Toxicol. Lett. 131 (12): 5-17.

Hufford, C.D., Clark, A.M., Quinones, I.N., Baker, J.K. and McChesney, J.D. 1983. Microbial metabolism studies on the major microbial and mammalian metabolite of primaquine. J. Pharm. Sci. 72(1) : 92-94.

Kolpin, D.W., Furlong, E.T., Meyer, M.T., Thurman, E.M., Zaugg, S.D., Barber, L.B. and Buxton, H.T. 2002. Pharmaceuticals, hormones, and other organic wastewater contaminants in U.S. streams, 19992000: A national reconnaissance. Environ. Sci. Toxicol. 36 : 1202-1211.

Parshikov I.A., Hernandes-Luna C.E., Zaraisky E.I. 2018a. Microbial transformation of the antimalarial and anticancer drug artemisinin by white-rot basidiomycetes. Asian Journal of Microbiology, Biotechnology and Environmental Sciences. 20(4) : 1093-1096.

Parshikov I.A. and Khasaeva F.M. 2018b. Fungal transformation of ofloxacin and enrofloxacin. Asian Journal of Microbiology, Biotechnology and Environmental Sciences. 20 (2) : 368-371.

Parshikov, I.A., Heinze, T.M., Williams, A.J., Moody, J.D., Freeman, J.P. and Suther, J.B. 2002. Biotransformation of the antibacterial agent cinoxacin by the fungus Beauveria bassiana. FEMS Microbiol. Lett. 214 : 133-136.

Vale, N., Moreira, R. and Gomes, P. 2009. Primaquine revisited six decades after its discovery. Eur. J. Med. Chem. 44(3): 937-953. 